\title{
Association between sitting time and non- alcoholic fatty liver disease in South Korean population: a cross-sectional study
}

\author{
Jae Hong Joo ${ }^{1,2}$, Hwi Jun Kim ${ }^{1,2,3}$, Eun-Cheol Park ${ }^{2,4}$ and Sung-In Jang ${ }^{2,4^{*}}$
}

\begin{abstract}
Background: To examine the association between sitting time and non-alcoholic fatty liver disease among South Koreans aged $\geq 20$ years.

Methods: Data from the 2016-2018 Korea National Health and Nutrition Examination Survey were used for the analysis. Non-alcoholic fatty liver disease was diagnosed according to a hepatic steatosis index of $>36$. Sitting time was categorized into as Q1, Q2, Q3, and Q4 using the age-adjusted quartile with Q4 being the longest sitting hour. Multiple logistic regression analysis was used to examine the association between sitting time and non-alcoholic fatty liver disease in South Korean population.

Results: A total of 13,518 participants were enrolled. The odds for having NAFLD in Q1, Q2, Q3, and Q4 (sitting hours) were 1.07 (Cl: 0.88-1.31), 1.16 (Cl: 1.96-1.41), and 1.34 (Cl: 1.11-1.61), respectively. The odds ratio increased in magnitude with longer hours of sitting time (test for trend: $P$-value $=0.0002$ ).

Conclusion: Advising physical exercises and discouraging sedentary activities may help to alleviate NAFLD among the South Korean population.

Keywords: Non-alcoholic fatty liver disease, Hepatic steatosis index, Sedentary, Sitting time, Physical activity, Obesity, South Korea
\end{abstract}

\section{Background}

Non-alcoholic fatty liver disease (NAFLD) is among the most common liver disorders, with approximately 9$30 \%$ of the population in developed countries having NAFLD [1, 2]. Fatty liver is often associated with heavy alcohol intake, but it may also occur in the absence of alcohol. The impact of globalization has led to a more westernized lifestyle and an increased frequency of obesity, and this contributed to an increased prevalence of NAFLD in the Asian countries [3,4]. The incidence of

\footnotetext{
* Correspondence: JANGSI@yuhs.ac

${ }^{2}$ Institute of Health Services Research, Yonsei University, 50 Yonsei-ro, Seodaemun-gu, Seoul 03722, Republic of Korea

${ }^{4}$ Department of Preventive Medicine, Yonsei University College of Medicine, 50 Yonsei-ro, Seodaemun-gu, Seoul 03722, Republic of Korea

Full list of author information is available at the end of the article
}

NAFLD is projected to increase due to the prevalence of sedentary behavior. If left untreated, NAFLD leads to end-stage liver disease. Thus, NAFLD is a serious public health burden that needs to be addressed and managed immediately [5].

Based on an evolutionary perspective, moving and engaging in every manner of manual labor was essential to survival of our species $[6,7]$. However, technological advances have created environments where sedentary lifestyle is encouraged and this is an increasing public health concern [8]. The prevalence of sedentary behavior is increasing in modern societies, and adults are becoming less active throughout the day [9]. Sedentary behavior involves sitting or lying down and not sufficiently spending energy substantially during the awake time 
[10]. There is increasing evidence that excessive sitting time is associated with higher risk for adverse health outcomes such as cardiovascular disease, type 2 diabetes, cancer, and mortality [11-13]. Maintaining balanced energy expenditure and physical activity is a key aspect of healthy behavior; thus, sedentary lifestyle should not be considered lightly.

A positive relationship between sedentary behavior and NAFLD has been reported persistently. NAFLD is closely linked to obesity, insulin resistance, metabolic disorders, and all of which are associated with excessive sedentary behavior $[14,15]$. Previously, a cross-sectional study conducted among the Chinese workers suggested that the positive association between sitting time and the prevalence NAFLD might be affected by inflammation [16]. The possible explanation for this finding might be the reduced circulating levels of aminotransferases and decreased hepatic steatosis mechanism linked to sedentary status [17]. Furthermore, other studies also demonstrated a close relationship between sedentary lifestyle and NAFLD [18-20]. These studies suggested that prolonged sitting time and decreased physical activity level were positively associated with the prevalence of NAFL $\mathrm{D}$, supporting the importance of reducing time spent sitting in addition to promoting physical activity.

The purpose of this study is to examine the association between sitting time and NAFLD in the South Korean population and to elucidate whether the prolonged sitting time plays a potential role in developing NAFLD.

\section{Methods}

\section{Study participants}

Data were obtained from the 2016-2018 Korea National Health and Nutrition Examination Survey (KNHANES), which was conducted by the Korea Centers for Disease Control and Prevention. The KNHANES is a self-report survey conducted in Koreans of all age and is designed to gather annual national data on sociodemographic, economic, and health-related conditions and behaviors. The survey is consisted of three components (health interview, health examination and nutrition survey), all of which are conducted by trained staff members including physicians and medical technicians [21].

The health interview and health examination are performed by trained medical staff and interviewers at the mobile examination center. One week after the health interview and health examination surveys, dieticians visit the homes of participants for the nutrition survey. The food frequency questionnaire is composed of 63 food items that are key sources of energy and nutrients. The food intake questionnaire has been designed as an openended survey for reporting various dishes and foods using the 24 -h recall method with various measuring aids.
Of the 24,269 survey participants, the study excluded who tested positive for serologic markers for liver disease (hepatitis B, hepatitis C, or liver cirrhosis) $(n=735)$, were aged $<20$ years who did not undergo blood testing conducted by the KNHANES $(n=6868)$, and were not representative of covariates considered in the study (failed to answer the survey questionnaires) $(n=3148)$. Accordingly, the final sample size consisted of 13,518 participants (Fig. 1). This study was an analysis of existing data; thus it did not require approval by ethics review board. The data that was used in this study is the KNHANES and it has been getting an annual review and approval by Korea Centers for Disease Control (KCDC) Research Ethics Review Committee since 2007.

This study investigated the effect of prolonged sitting particularly on NAFLD. The participants with FLD related to alcohol were eliminated during the process of comprising the study sample. FLD related to alcohol was determined by biochemical and clinical profiles of the participants that were examined by the KNHANES's trained staff members (i.e. physicians and medical technicians) [21].

\section{NAFLD classification}

NAFLD is the main dependent variable in this study. NAFLD in this study was diagnosed according to the hepatic steatosis index (HSI), which was developed by the Department of Internal Medicine and Liver Research Institute in Seoul National University College of Medicine to efficiently select individuals for liver ultrasonography ${ }^{22}$. The HSI formula was derived via logistic regression model using serum alanine aminotransferase (ALT) to serum aspartate aminotransferase (AST) ratio, body mass index (BMI), and diabetes mellitus status: $\mathrm{HSI}=8 \times($ ALT $/ \mathrm{AST}$ ratio $)+\mathrm{BMI}(+2$, if female; +2 , if with diabetes mellitus) [22]. Participants were considered to have NAFLD if their HSI value was above 36.

\section{Sitting time}

The main independent variable is the participants' sitting time. Sitting time was measured by asking participants to report the following question adopted from the longversion of the International Physical Activity Questionnaire (IPAQ) [23, 24]. The overall daily sitting time was estimated particularly following questions: How many hours do you typically spend sitting or lying down while engaged in activities such as working at a desk or computer, visiting friends, driving, reading, writing, watching television, playing games, using the Internet, or listening to music on a usual day? Participants' responses to sitting time were divided into 4 categories using ageadjusted quartile (Table 1 ). 


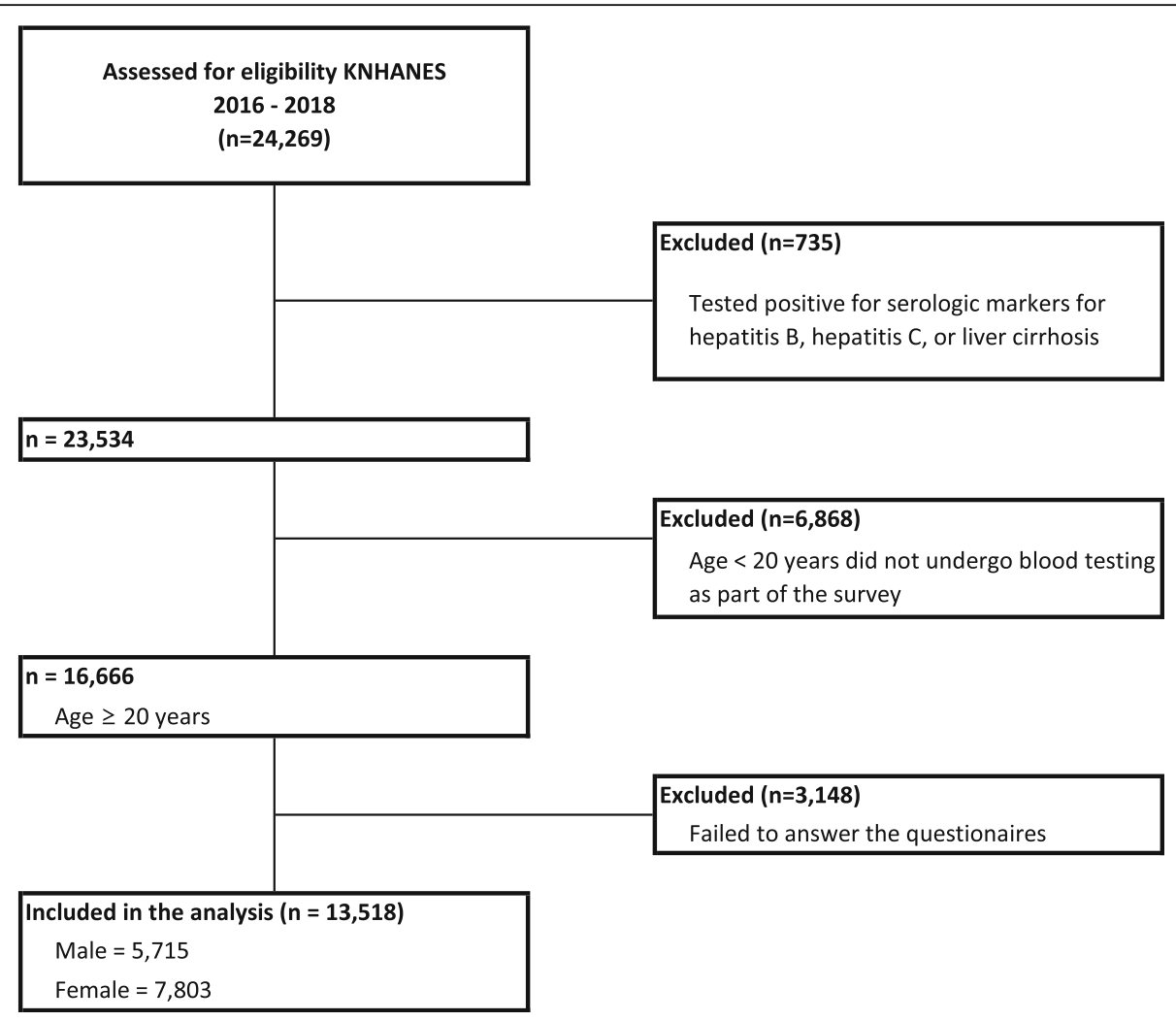

Fig. 1 Flow diagram of subject inclusion and exclusion

\section{Covariates}

Sociodemographic, economic, and health-related factors were also considered in the study. Sociodemographic factors included age, educational attainment, and marital status. Economic factors included household income and occupation. Health-related factors include sleeping time (hours), total energy intake ((carbohydrate $(\mathrm{g}) \times 4 \mathrm{kcal} / \mathrm{g})+$ $(\operatorname{protein}(\mathrm{g}) \times 4 \mathrm{kcal} / \mathrm{g})+(\mathrm{fat}(\mathrm{g}) \times 9 \mathrm{kcal} / \mathrm{g}))$, daily physical activity level based on the KNHANES questionnaire which was adopted from the World Health Organization guideline (active: $\geq 150 \mathrm{~min}$ of moderate activity, $\geq 75 \mathrm{~min}$ of vigorous activity, or a mixture of both for $\geq 150 \mathrm{~min}$; inactive: $<150 \mathrm{~min}$ of moderate activity, $<75 \mathrm{~min}$ of vigorous activity, or a mixture of both for $<150 \mathrm{~min}$ ) [25], pack years of smoking, current drinking status, comorbidity of hypertension, and comorbidity of diabetes mellitus.

\section{Statistical analysis}

The frequencies and percentages of participants were calculated for each of the categorized variables included in the study. The variables included in the analysis were all categorical, those that were not initially categorical were converted into categories (age, BMI, total energy intake). The chi-square $\left(\chi^{2}\right)$ test was performed to assess the chi-square differences between the groups within each categorized variable (Table 2). Multiple logistic regression analysis was used to calculate the odds ratios (with 95\% confidence intervals) for NAFLD according to

Table 1 Age-adjusted sitting time categorized using quartile

\begin{tabular}{|c|c|c|c|c|c|c|c|}
\hline \multirow{2}{*}{$\begin{array}{l}\text { Age } \\
\text { group }\end{array}$} & \multirow[t]{2}{*}{$\mathbf{N}$} & \multicolumn{6}{|c|}{ Sitting time (hr) } \\
\hline & & Q1 & Median & Q3 & Max & Mean & SD \\
\hline $20-29$ & 1609 & 7 & 10 & 12 & 20 & 9.56 & 3.45 \\
\hline $30-39$ & 2167 & 5 & 8 & 10 & 18 & 8.32 & 3.47 \\
\hline $40-49$ & 2558 & 5 & 8 & 10 & 19 & 7.92 & 3.40 \\
\hline $50-59$ & 2551 & 5 & 7 & 10 & 20 & 7.28 & 3.34 \\
\hline $60-69$ & 2416 & 5 & 7 & 10 & 22 & 7.32 & 3.38 \\
\hline$\geq 70$ & 2217 & 6 & 8 & 12 & 20 & 8.74 & 3.70 \\
\hline
\end{tabular}


Table 2 General characteristics of the study population

\begin{tabular}{|c|c|c|c|c|c|c|c|}
\hline \multirow[t]{3}{*}{ Variables } & \multicolumn{7}{|c|}{ Non-alcoholic fatty liver disease (NAFLD) } \\
\hline & \multicolumn{2}{|c|}{ TOTAL } & \multicolumn{2}{|c|}{ Yes $^{\mathrm{a}}$} & \multicolumn{2}{|l|}{$\mathrm{No}^{\mathrm{b}}$} & \multirow[t]{2}{*}{ P-value* } \\
\hline & $\mathrm{N}$ & $\%$ & $\mathrm{~N}$ & $\%$ & $\mathrm{~N}$ & $\%$ & \\
\hline Total & 13,518 & 100.0 & 3140 & 23.2 & 10,378 & 76.8 & \\
\hline Age-adjusted sitting time $(\mathrm{hr})^{\mathrm{c}}$ & & & & & & & $<.0001$ \\
\hline Q1 (lower < 25\%) & 2802 & 26.1 & 566 & 20.2 & 2236 & 79.8 & \\
\hline Q2 & 2816 & 26.3 & 629 & 22.3 & 2187 & 77.7 & \\
\hline Q3 & 3519 & 32.8 & 798 & 22.7 & 2721 & 77.3 & \\
\hline Q4 (upper > 75\%) & 4381 & 40.9 & 1147 & 26.2 & 3234 & 73.8 & \\
\hline Sex & & & & & & & $<.0001$ \\
\hline Male & 5715 & 53.3 & 1539 & 26.9 & 4176 & 73.1 & \\
\hline Female & 7803 & 72.8 & 1601 & 20.5 & 6202 & 79.5 & \\
\hline Age & & & & & & & $<.0001$ \\
\hline $20-29$ & 1609 & 15.0 & 308 & 19.1 & 1301 & 80.9 & \\
\hline $30-39$ & 2167 & 20.2 & 545 & 25.1 & 1622 & 74.9 & \\
\hline $40-49$ & 2558 & 23.9 & 615 & 24.0 & 1943 & 76.0 & \\
\hline $50-59$ & 2551 & 23.8 & 633 & 24.8 & 1918 & 75.2 & \\
\hline $60-69$ & 2416 & 22.5 & 597 & 24.7 & 1819 & 75.3 & \\
\hline$\geq 70$ & 2217 & 20.7 & 442 & 19.9 & 1775 & 80.1 & \\
\hline Marital status & & & & & & & 0.0443 \\
\hline Married and living together & 9499 & 88.6 & 2177 & 22.9 & 7322 & 77.1 & \\
\hline $\begin{array}{l}\text { Living apart, divorced, or } \\
\text { deceased }\end{array}$ & 1781 & 16.6 & 455 & 25.5 & 1326 & 74.5 & \\
\hline Unmarried & 2238 & 20.9 & 508 & 22.7 & 1730 & 77.3 & \\
\hline Educational attainment & & & & & & & $<.0001$ \\
\hline$\leq$ Highschool & 8350 & 77.9 & 2048 & 24.5 & 6302 & 75.5 & \\
\hline$\geq$ College & 5168 & 48.2 & 1092 & 21.1 & 4076 & 78.9 & \\
\hline Occupation $^{d}$ & & & & & & & 0.0099 \\
\hline White-color & 3429 & 32.0 & 750 & 21.9 & 2679 & 78.1 & \\
\hline Blue-color & 3106 & 29.0 & 764 & 24.6 & 2342 & 75.4 & \\
\hline Pink-color & 1716 & 16.0 & 432 & 25.2 & 1284 & 74.8 & \\
\hline Unemployed & 5267 & 49.2 & 1194 & 22.7 & 4073 & 77.3 & \\
\hline Household income & & & & & & & $<.0001$ \\
\hline Low & 2472 & 23.1 & 612 & 24.8 & 1860 & 75.2 & \\
\hline Mid-low & 3290 & 30.7 & 803 & 24.4 & 2487 & 75.6 & \\
\hline Mid-high & 3739 & 34.9 & 896 & 24.0 & 2843 & 76.0 & \\
\hline High & 4017 & 37.5 & 829 & 20.6 & 3188 & 79.4 & \\
\hline Sleeping time (hr) & & & & & & & $<.0001$ \\
\hline$<7$ & 5010 & 46.8 & 1256 & 25.1 & 3754 & 74.9 & \\
\hline$\geq 7$ & 8508 & 79.4 & 1884 & 22.1 & 6624 & 77.9 & \\
\hline Energy intake (kcal) ${ }^{\mathbf{e}}$ & & & & & & & 0.9991 \\
\hline Quintile 1 (lower < 20\%) & 2703 & 25.2 & 623 & 23.0 & 2080 & 77.0 & \\
\hline Quintile 2 & 2704 & 25.2 & 627 & 23.2 & 2077 & 76.8 & \\
\hline Quintile 3 & 2703 & 25.2 & 628 & 23.2 & 2075 & 76.8 & \\
\hline Quintile 4 & 2705 & 25.2 & 631 & 23.3 & 2074 & 76.7 & \\
\hline Quintile 5 (upper $>80 \%$ ) & 2703 & 25.2 & 631 & 23.3 & 2072 & 76.7 & \\
\hline
\end{tabular}


Table 2 General characteristics of the study population (Continued)

\begin{tabular}{|c|c|c|c|c|c|c|c|}
\hline \multirow[t]{3}{*}{ Variables } & \multicolumn{7}{|c|}{ Non-alcoholic fatty liver disease (NAFLD) } \\
\hline & \multicolumn{2}{|c|}{ TOTAL } & \multicolumn{2}{|c|}{$Y_{e s}{ }^{a}$} & \multicolumn{2}{|l|}{$\mathrm{No}^{\mathrm{b}}$} & \multirow[t]{2}{*}{$P$-value* } \\
\hline & $\mathrm{N}$ & $\%$ & $\mathrm{~N}$ & $\%$ & $\mathrm{~N}$ & $\%$ & \\
\hline Physical activeness & & & & & & & 0.0017 \\
\hline Active & 5913 & 55.2 & 1297 & 21.9 & 4616 & 78.1 & \\
\hline Inactive & 7605 & 71.0 & 1843 & 24.2 & 5762 & 75.8 & \\
\hline Pack years of smoking & & & & & & & $<.0001$ \\
\hline$\geq 5$ packs & 4884 & 45.6 & 1265 & 25.9 & 3619 & 74.1 & \\
\hline$<5$ packs & 275 & 2.6 & 65 & 23.6 & 210 & 76.4 & \\
\hline Never & 8359 & 78.0 & 1810 & 21.7 & 6549 & 78.3 & \\
\hline Current drinking status & & & & & & & 0.0019 \\
\hline 2-4 times / week & 2973 & 27.7 & 647 & 21.8 & 2326 & 78.2 & \\
\hline 2-4 times / month & 3047 & 28.4 & 665 & 21.8 & 2382 & 78.2 & \\
\hline Never or occasionally & 7498 & 70.0 & 1828 & 24.4 & 5670 & 75.6 & \\
\hline Obesity status defined by BMI & & & & & & & $<.0001$ \\
\hline Obese $\left(\geq 25 \mathrm{~kg} / \mathrm{m}^{2}\right)$ & 6765 & 63.1 & 2963 & 43.8 & 3802 & 56.2 & \\
\hline $\begin{array}{l}\text { Normal or borderline } \\
\left(<25 \mathrm{~kg} / \mathrm{m}^{2}\right)\end{array}$ & 6753 & 63.0 & 177 & 2.6 & 6576 & 97.4 & \\
\hline Hypertension & & & & & & & $<.0001$ \\
\hline Hypertension & 4298 & 40.1 & 1454 & 33.8 & 2844 & 66.2 & \\
\hline Prehypertension & 3260 & 30.4 & 867 & 26.6 & 2393 & 73.4 & \\
\hline Normal & 5960 & 55.6 & 819 & 13.7 & 5141 & 86.3 & \\
\hline Diabetes & & & & & & & $<.0001$ \\
\hline Diabetes & 1673 & 15.6 & 843 & 50.4 & 830 & 49.6 & \\
\hline Impaired fasting glucose & 3253 & 30.4 & 982 & 30.2 & 2271 & 69.8 & \\
\hline Normal & 8592 & 80.2 & 1315 & 15.3 & 7277 & 84.7 & \\
\hline Year & & & & & & & 0.0293 \\
\hline 2016 & 4347 & 40.6 & 1065 & 24.5 & 3282 & 75.5 & \\
\hline 2017 & 4511 & 42.1 & 998 & 22.1 & 3513 & 77.9 & \\
\hline 2018 & 4660 & 43.5 & 1077 & 23.1 & 3583 & 76.9 & \\
\hline
\end{tabular}

Hepatic steatosis index $=8 \times($ ALT/AST ratio $)+B M I(+2$, if female +2 , if diabetes mellitus $))$

${ }^{a}$ Hepatic steatosis index $\geq 36$

${ }^{b}$ Hepatic steatosis index $<36$

${ }^{\mathrm{c}}$ Age-adjusted sitting-time categorized using quartile (see Table 1)

${ }^{\mathrm{d} C}$ Categories based on International Standard Classification Occupations codes

${ }^{\mathrm{e}}$ Total energy intake $=($ carbohydrate $(\mathrm{g}) \times 4 \mathrm{kcal} / \mathrm{g})+($ protein $(\mathrm{g}) \times 4 \mathrm{kcal} / \mathrm{g})+(\mathrm{fat}(\mathrm{g}) \times 9 \mathrm{kcal} / \mathrm{g})$;

fObesity status defined by BMI based on 2014 Clinical Practice Guidelines for Overweight and Obesity in Korea

*Measure for chi-squire differences between groups within each category (significant level: $P$-value $<0.05$ )

the participants' report on sitting time (Table 3). The sub-group analysis for NAFLD stratified by the participants' sex, physical activeness, and obesity status defined by BMI was also performed using multiple logistic regression (Fig. 2).

The reported odds ratios were adjusted for all covariates considered in the study. The sampling weight variables were applied in the analysis to improve the representativeness of the sample. KNHANES has constructed sample weights to take into account survey non-response, oversampling, post-stratification, and sampling error. The use of sample weights in the analysis is recommended to produce an unbiased national estimate. For all data analysis, SAS version 9.4 (SAS Institute, Inc., Cary, NC, USA) was used and the significance level was set at $P$-value < 0.05 .

\section{Results}

The general characteristics of the study population are shown in Table 2. Of 13,518 participants, 3140 (23.2\%) reported had NAFLD. The frequencies of having NAFL $\mathrm{D}$ varied across the different sitting hour categories. The participants who reported the longest hours of sitting per day (Q4) had the highest frequency of having NAFL 
Table 3 Odds ratio for NAFLD

\begin{tabular}{|c|c|c|c|c|c|}
\hline \multirow[t]{2}{*}{ Variables } & \multicolumn{5}{|c|}{ Non-alcoholic fatty liver disease (NAFLD) } \\
\hline & $\mathrm{OR}^{\mathrm{a}}$ & $95 \% \mathrm{Cl}$ & $\beta$ & SE & $P$-value \\
\hline \multicolumn{6}{|l|}{ Age-adjusted sitting time $(\mathrm{hr})^{\mathbf{b}}$} \\
\hline Q1 (lower < 25\%) & 1.00 & & Ref. & & \\
\hline Q2 & 1.07 & $(0.88-1.31)$ & 0.07 & 0.10 & 0.4968 \\
\hline Q3 & 1.16 & $(0.96-1.41)$ & 0.15 & 0.10 & 0.1184 \\
\hline Q4 (upper > 75\%) & 1.34 & $(1.11-1.61)$ & 0.29 & 0.09 & 0.0022 \\
\hline Test for trend & \multicolumn{5}{|c|}{$P$-value $=0.0002$} \\
\hline \multicolumn{6}{|l|}{ Sex } \\
\hline Male & 1.00 & & Ref. & & \\
\hline Female & 0.91 & $(0.76-1.09)$ & -0.09 & 0.09 & 0.3063 \\
\hline \multicolumn{6}{|l|}{ Marital status } \\
\hline Married and living together & 1.00 & & Ref. & & \\
\hline Living apart, divorced, or deceased & 1.09 & $(0.90-1.33)$ & 0.09 & 0.10 & 0.3894 \\
\hline Unmarried & 1.25 & $(0.97-1.60)$ & 0.22 & 0.13 & 0.0801 \\
\hline \multicolumn{6}{|l|}{ Educational attainment } \\
\hline$\leq$ Highschool & 1.08 & $(0.93-1.27)$ & 0.08 & 0.08 & 0.3195 \\
\hline$\geq$ College & 1.00 & & Ref. & & \\
\hline \multicolumn{6}{|l|}{ Occupation $^{c}$} \\
\hline White-color & 1.00 & & Ref. & & \\
\hline Blue-color & 0.95 & $(0.79-1.15)$ & -0.05 & 0.10 & 0.6055 \\
\hline Pink-color & 1.19 & $(0.94-1.49)$ & 0.17 & 0.12 & 0.1420 \\
\hline Unemployed & 1.29 & $(1.07-1.54)$ & 0.25 & 0.09 & 0.0067 \\
\hline \multicolumn{6}{|l|}{ Household income } \\
\hline Low & 1.08 & $(0.87-1.35)$ & 0.08 & 0.11 & 0.4851 \\
\hline Mid-low & 1.06 & $(0.90-1.26)$ & 0.06 & 0.09 & 0.4740 \\
\hline Mid-high & 1.18 & $(1.00-1.39)$ & 0.17 & 0.08 & 0.0461 \\
\hline High & 1.00 & & Ref. & & \\
\hline \multicolumn{6}{|l|}{ Sleeping time (hr) } \\
\hline$<7$ & 1.01 & $(0.89-1.14)$ & 0.01 & 0.06 & 0.9237 \\
\hline$\geq 7$ & 1.00 & & Ref. & & \\
\hline \multicolumn{6}{|l|}{ Energy intake ${ }^{d}$} \\
\hline Quintile 1 (lower < 20\%) & 0.90 & $(0.75-1.09)$ & -0.10 & 0.09 & 0.2898 \\
\hline Quintile 2 & 0.86 & $(0.70-1.05)$ & -0.16 & 0.10 & 0.1274 \\
\hline Quintile 3 & 1.00 & & Ref. & & \\
\hline Quintile 4 & 0.99 & $(0.83-1.19)$ & -0.01 & 0.09 & 0.9468 \\
\hline Quintile 5 (upper > 80\%) & 1.05 & $(0.86-1.28)$ & 0.05 & 0.10 & 0.6521 \\
\hline \multicolumn{6}{|l|}{ Physical activeness } \\
\hline Active & 1.00 & & Ref. & & \\
\hline Inactive & 1.31 & $(1.16-1.48)$ & 0.27 & 0.06 & $<.0001$ \\
\hline \multicolumn{6}{|l|}{ Pack years of smoking } \\
\hline$\geq 5$ packs & 0.99 & $(0.84-1.18)$ & -0.01 & 0.09 & 0.9391 \\
\hline$<5$ packs & 0.93 & $(0.59-1.45)$ & -0.08 & 0.23 & 0.7371 \\
\hline Never & 1.00 & & Ref. & & \\
\hline
\end{tabular}


Table 3 Odds ratio for NAFLD (Continued)

\begin{tabular}{|c|c|c|c|c|c|}
\hline \multirow[t]{2}{*}{ Variables } & \multicolumn{5}{|c|}{ Non-alcoholic fatty liver disease (NAFLD) } \\
\hline & $\overline{O R^{a}}$ & $95 \% \mathrm{Cl}$ & $\beta$ & SE & $P$-value \\
\hline \multicolumn{6}{|l|}{ Current drinking status } \\
\hline 2-4 times / week & 0.50 & $(0.42-0.59)$ & -0.70 & 0.09 & $<.0001$ \\
\hline 2-4 times / month & 0.75 & $(0.64-0.88)$ & -0.29 & 0.08 & 0.0005 \\
\hline Never or occasionally & 1.00 & & Ref. & & \\
\hline \multicolumn{6}{|l|}{ Obesity status defined by $\mathrm{BMI}^{\mathrm{e}}$} \\
\hline Obese $\left(\geq 25 \mathrm{~kg} / \mathrm{m}^{2}\right)$ & 38.93 & $(31.62-47.92)$ & 3.66 & 0.11 & $<.0001$ \\
\hline Normal or borderline $\left(<25 \mathrm{~kg} / \mathrm{m}^{2}\right)$ & 1.00 & & Ref. & & \\
\hline \multicolumn{6}{|l|}{ Hypertension } \\
\hline Hypertension & 2.29 & $(1.93-2.73)$ & 0.83 & 0.09 & $<.0001$ \\
\hline Prehypertension & 1.85 & $(1.58-2.17)$ & 0.62 & 0.08 & $<.0001$ \\
\hline Normal & 1.00 & & Ref. & & \\
\hline \multicolumn{6}{|l|}{ Diabetes } \\
\hline Diabetes & 7.19 & $(5.91-8.73)$ & 1.97 & 0.10 & $<.0001$ \\
\hline Impaired fasting glucose & 1.90 & $(1.65-2.19)$ & 0.64 & 0.07 & $<.0001$ \\
\hline Normal & 1.00 & & Ref. & & \\
\hline \multicolumn{6}{|l|}{ Year } \\
\hline 2016 & 1.00 & & Ref. & & \\
\hline 2017 & 0.37 & $(0.32-0.44)$ & -0.98 & 0.09 & $<.0001$ \\
\hline 2018 & 0.40 & $(0.35-0.47)$ & -0.91 & 0.08 & $<.0001$ \\
\hline 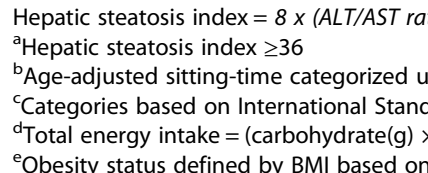 & female; & s mellitus)) & & & \\
\hline
\end{tabular}

D (26.2\%), whereas those who reported the shortest hours of sitting per day (Q1) had the lowest frequency of having NAFLD (20.2\%) among the study sample.

Based on the odds ratios calculated from the multiple logistic analysis, the relationship between NAFLD and sitting time was analyzed along with other covariates. The participants in the Q1 group served as the reference group in this study and the relative risk for other 'sitting time' groups are expressed in Table 3. The odds for NAFLD in 'Q2', 'Q3', and 'Q4' were 1.07 (CI: 0.88-1.31), 1.16 (CI: 1.96-1.41), and 1.34 (CI: $1.11-1.61)$, respectively. The odds ratio increase in magnitude with longer hours of sitting time was tested for statistical significance using the linear trend test (test for trend: $P$-value $=0.0002$ ).

Odds ratio for NAFLD according to the participants' sitting time was stratified by sex, physical activity level, and obesity status (Fig. 2). In this analysis, 'Q1' group were again served as the reference group. In both sexes, those who are in the Q4 group had relatively higher odds compared to those who reported shorter amount of sitting time (male 1.32, CI: 0.99-1.76; female 1.33, CI: 1.03-1.72). When participants were stratified by their physical activeness, the significant results were only observed in physically inactive group. Those who are in the Q4 group had the highest odds (1.84, CI: 1.42-2.38) within the physically inactive group and it was also the higher when compared to their physically active courterparts. Moreover, the risk of having NAFLD was relatively high in those who are in the Q3 group (1.28, CI: 1.02-1.59) and Q4 (1.33, CI: 1.091.64) among the obese participants.

\section{Discussion}

The overall findings were that there is an association of sitting time with NAFLD and the risk of having NAFLD increases in magnitude with longer hours of sitting.

Sedentary behavior, which is characterized by a lack of muscle movement, directly affects cardiometabolic function ${ }^{6}$. The human body is designed to move, and previous studies reported that inactivity results in impaired lipid steatosis and insulin resistance [26, 27]. This aligns with findings of this study which suggest that a higher rate of NAFLD was observed in sedentary participants. Prolonged sitting is correlated with higher BMI, body fat, and circulatory lipids, all of which are associated with liver lipid content [28]. Cumulative fat in the mitochondria, one of the key regulators of liver pathophysiology, 


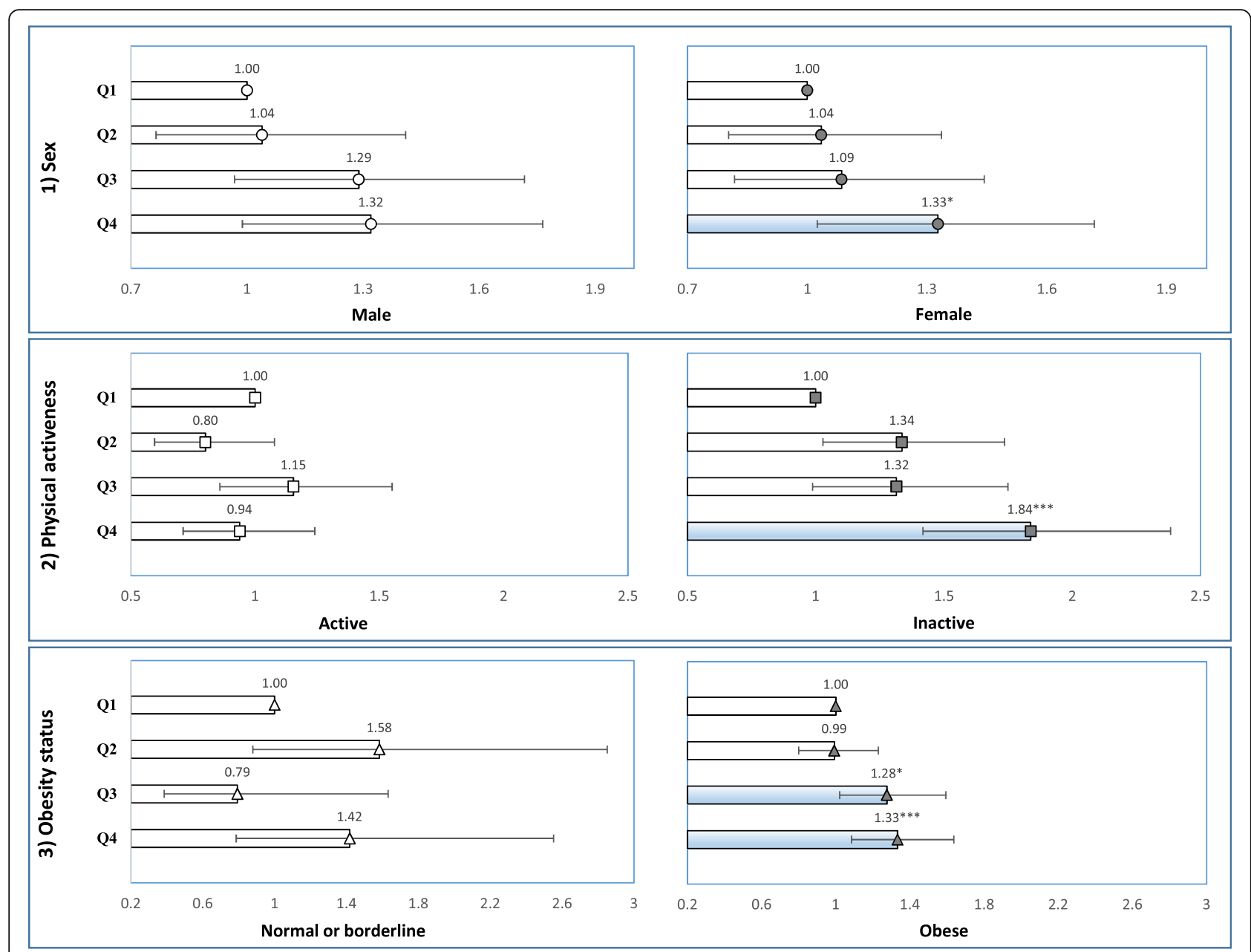

Fig. 2 Forest plot representing odds ratio for NAFLD according to the participants' age-adjusted sitting time stratified by 1) sex, 2) physical activeness, and 3 ) obesity status defined by BMI. ${ }^{*} P$-value $<0.05$, ${ }^{* * *} P$-value $<0.01$

progresses to non-alcoholic steatohepatitis with inflammation [29]. Mitochondrial dysfunction disrupts the encoding of cytochromes during carcinogenesis, and this leads to increased reactive oxygen species (ROS) production. Fat disposition in the liver may be because of ROS proliferation in Kupffer cells and hepatocytes [30].

To date, lifestyle modification remains as one of the most important option in NAFLD management. The situation with respect to sedentary behavior, however, is remained widely unexplored. Thus, the present study aimed to validate the association between prolonged sitting time and NAFLD and clarify what other factors might play a potential role in developing NAFLD in the general South Korean population.

In recent years, it has been reported that sedentarism is a risk factor for numerous negative health outcomes, independent of exercise, and that increasing structured exercise time does not counteract sitting time [12, 31-33]. The present study clarified these previous findings by examining the odds for NAFLD according to the participants' sitting time and simultaneously adjusting for the participants' physical activeness along with other covariates. This was typically done so that the physical activity can no longer act as a confounder. This study supports the evidence that the risk for NAFLD increases in magnitude with longer hours of sitting. Furthermore, the subgroup analysis was performed to examine the combined interactions between prolonged sitting time and physical activity on NAFLD. It seemed that the risk for NAFLD is relatively high for the people in the Q4 group who were also physically inactive. Thus, suggesting that physical inactivity in conjunction with prolonged sitting can potentially increase the probability of having NAFLD.

In this study, the probability of having NAFLD was relatively high in participants who were sedentary and physically inactive. Physical activity is the primary strategy for managing NAFLD. Gains in physical activity improves serum liver enzymes, reduces hepatic fatty infiltration, and reduces a degree of hepatic inflammation and fibrosis, all of which contribute to health benefits 
beyond the prevention of NAFLD [34]. The benefits of exercise and fitness have been supported by results of previous clinical trials. Normalized level of ALT and significant weight loss were observed in participants who increased their physical activity $[35,36]$. Regular physical activity is important because the frequency and intensity of physical activity are strong factors for predicting a person's hepatic outcome.

Primarily, NAFLD is a consequence of insulin resistance, and thus occurs frequently among obese participants [37]. This study's results showed that the risk of developing NAFLD is higher in obese participants who were more likely to be sedentary. Obesity is associated with increased visceral fat that releases free fatty acids into the hepatic portal circulation and the concentration of free fatty acids serves as the key mediator of insulin resistance [38]. The absence of physical activity aggravates insulin sensitivity and glucose homeostasis. Sedentary behavior causes downregulation of insulin receptor in muscle tissue $[39,40]$. This means that prolonged sitting and physical inactivity impairs the delivery of insulin and glucose to the muscle and hence deteriorate the metabolism of free fatty acid [41].

\section{Study strength and limitations}

The strength of the study is that the dataset generated from the KNHANES is nationally representative of the health status in South Korea. KNHANES questionnaires are updated annually to incorporate the changes in the real-life health circumstances of South Koreans. KNHA NES has been extremely useful in health-related studies and provides meaningful insights for South Korean health policies. This study has several limitations. First, although HSI has been proven to have high sensitivity for detecting NAFLD (sensitivity of $93.1 \%$ and specificity of 92.4\%) [22], there are still tiny odds of false-positive or false negative. Second, this is study was a crosssectional study and was unable to provide a causal relation between sitting time and NAFLD. Third, the KNHA NES uses self-report questionnaires, and thus the data extracted may have been subject to recall bias.

\section{Conclusion}

This study found that prolonged sitting time (sitting time of $>10 \mathrm{~h} /$ day) was associated with NAFLD among the South Korean population aged $>20$ years. The adverse effect of sitting time on NAFLD was mediated by physical inactiveness and obesity. The findings of this study suggest that lifestyle modifications to engage in physical activity and reduce weight could contribute to managing and preventing NAFLD in the South Korean population. Interventions on sitting time may provide a new solution for the prevention of NAFLD in South Korea.

\section{Acknowledgements}

We thank the Korean Centers for Disease Control (KCDC) which produced and provided national level survey data. We also thank those colleagues of the Institute of Health Services Research in Yonsei University that have given advice for important intellectual content.

\section{Authors' contributions}

JH.J., EC.P., and SI.J. designed the study, collected the data, performed the statistical analysis, and wrote the manuscript. H.K. contributed to the discussion and reviewed and edited the manuscript. SI.J. is the guarantor of this work and as such, had full access to all of the data. SI.J. assumes responsibility for the integrity of the data and the accuracy of the data analysis. The author(s) read and approved the final manuscript.

\section{Funding}

This study was supported by a faculty research grand of Yonsei Univesity College of Medicine (6-2018-0174 and 6-2017-0157).

\section{Availability of data and materials}

The KNHANES was openly available in https://knhanes.cdc.go.kr/knhanes/ index.do by submitting written oath and data utilization plan.

\section{Ethics approval and consent to participate}

This study was an analysis of existing data; thus it did not require approval by ethics review board. The data that was used in this study is the KNHANES and it has been getting an annual review and approval by Korea Centers for Disease Control (KCDC) Research Ethics Review Committee since 2007.

\section{Consent for publication}

Not applicable.

\section{Competing interests}

The authors declare that they have no competing interest.

\section{Author details}

${ }^{1}$ Department of Public Health, Graduate School, Yonsei University, Seoul, Republic of Korea. ${ }^{2}$ Institute of Health Services Research, Yonsei University, 50 Yonsei-ro, Seodaemun-gu, Seoul 03722, Republic of Korea. ${ }^{3} 27$ th Infantry Division Medical Dispensary Operation Branch, Hwacheon, Republic of Korea. ${ }^{4}$ Department of Preventive Medicine, Yonsei University College of Medicine, 50 Yonsei-ro, Seodaemun-gu, Seoul 03722, Republic of Korea.

Received: 2 July 2020 Accepted: 6 September 2020

Published online: 23 September 2020

\section{References}

1. Armstrong MJ, Houlihan DD, Bentham L, et al. Presence and severity of non-alcoholic fatty liver disease in a large prospective primary care cohort. J Hepatology. 2012:56(1):234-40.

2. Cichoż-Lach H, Celiński K, Prozorow-Król B, Swatek J, Słomka M, Lach T. The BARD score and the NAFLD fibrosis score in the assessment of advanced liver fibrosis in nonalcoholic fatty liver disease. Med Sci Mon. 2012;18(12): CR735-40.

3. Loomba R, Sanyal AJ. The global NAFLD epidemic. Nat Rev Gastroenterol Hepatol. 2013;10(11):686-90.

4. Lim YS, Kim WR. The global impact of hepatic fibrosis and end-stage liver disease. Clinics in Liver Disease. 2008;12(4):733-46 vii.

5. Lee Y-h, Kim SU, Song K, et al. Sarcopenia is associated with significant liver fibrosis independently of obesity and insulin resistance in nonalcoholic fatty liver disease: Nationwide surveys (KNHANES 2008-2011). Hepatology (BaltimoreMd). 2016;63(3):776-86.

6. Owen N, Sparling PB, Healy GN, Dunstan DW, Matthews CE. Sedentary behavior: emerging evidence for a new health risk. Mayo Clin Proc. 2010; 85(12):1138-41.

7. Hill JO, Wyatt HR, Reed GW, Peters JC. Obesity and the environment: where do we go from here? Science. 2003;299(5608):853.

8. Dzewaltowski DA. Emerging technology, physical activity, and sedentary behavior. Exercise and Sport Sciences Review. 2008;36(4):171-2.

9. Knaeps S, Bourgois JG, Charlier R, Mertens E, Lefevre J, Wijndaele K. Ten-year change in sedentary behaviour, moderate-to-vigorous physical activity, 
cardiorespiratory fitness and cardiometabolic risk: independent associations and mediation analysis. Br J Sports Med. 2018;52(16):1063.

10. Tremblay M. Letter to the editor: standardized use of the terms "sedentary" and "sedentary behaviours". Appl Physiol Nutr Metab. 2012;37(3):540-2.

11. Proper KI, Singh AS, van Mechelen W, Chinapaw MJM. Sedentary behaviors and health outcomes among adults: a systematic review of prospective studies. Am J Prev Med 2011;40(2):174-182.

12. Thorp AA, Owen N, Neuhaus M, Dunstan DW. Sedentary behaviors and subsequent health outcomes in adults: a systematic review of longitudinal studies, 1996-2011. Am J Prev Med. 2011;41(2):207-15.

13. van der Ploeg HP, Chey T, Korda RJ, Banks E, Bauman A. Sitting time and allcause mortality risk in 222497 australian adults. Arch Intern Med. 2012; 172(6):494-500

14. Zelber-Sagi S, Lotan R, Shlomai A, et al. Predictors for incidence and remission of NAFLD in the general population during a seven-year prospective follow-up. J Hepatol. 2012;56(5):1145-51.

15. Kumashiro N, Erion DM, Zhang D, et al. Cellular mechanism of insulin resistance in nonalcoholic fatty liver disease. Proc Natl Acad Sci U S A. 2011; 108(39):16381-5.

16. Wei H, Qu H, Wang H, Deng H. Associations between sitting time and nonalcoholic fatty liver diseases in Chinese male workers: a cross-sectional study. BMJ Open. 2016;6(9):e011939.

17. Kistler KD, Brunt EM, Clark JM, et al. Physical activity recommendations, exercise intensity, and histological severity of nonalcoholic fatty liver disease. Am J Gastroenterol. 2011;106(3):460.

18. Fan J-G, Kim S-U, Wong WW-S. New trends on obesity and NAFLD in Asia. J Hepatol. 2017;67(4):862-73.

19. Ryu S, Chang Y, Jung H-S, et al. Relationship of sitting time and physical activity with non-alcoholic fatty liver disease. J Hepatol. 2015;63(5):1229-37.

20. Hallsworth K, Thoma C, Moore S, et al. Non-alcoholic fatty liver disease is associated with higher levels of objectively measured sedentary behaviour and lower levels of physical activity than matched healthy controls. Frontline Gasteroenterology. 2015;6(1):44-51.

21. Kweon S, Kim Y, M-j J, et al. Data resource profile: the Korea National Health and nutrition examination survey (KNHANES). Int J Epidemiol. 2014;43(1):69-77.

22. Lee JH, Kim D, Kim HJ, et al. Hepatic steatosis index: a simple screening tool reflecting nonalcoholic fatty liver disease. Dig Liver Dis. 2010;42(7):503-8.

23. Oh JY, Yang YJ, Kim BS, Kang JH. Validity and reliability of Korean version of international physical activity questionnaire (IPAQ) short form. J Korean Acad Fam Med. 2007;28(7):532-41.

24. Rosenberg DE, Bull FC, Marshall AL, Sallis JF, Bauman AE. Assessment of sedentary behavior with the international physical activity questionnaire. Journal of Physical Activity. 2008:5(s1):S30-44.

25. WHO. Physical activity and adults: recommended levels of physical activity for adults aged 18-64 years. Global strategy on diet, physical activity and health 2016 [cited 202013 Aug]; Available from: http://www.who.int/ dietphysicalactivity/factsheet_adults/en/.

26. Ekblom Ö, Ekblom-Bak E, Rosengren A, Hallsten M, Bergström G, Börjesson M. Cardiorespiratory fitness, sedentary behaviour and physical activity are independently associated with the metabolic syndrome, results from the SCAPIS pilot study. PLoS One. 2015;10(6):e0131586.

27. Yates T, Khunti K, Wilmot EG, et al. Self-reported sitting time and markers of inflammation, insulin resistance, and adiposity. Am J Prev Med. 2012;42(1):1-7.

28. Trenell MI. Sedentary behaviour, physical activity, and NAFLD: curse of the chair. J Hepatol. 2015;63(5):1064-5.

29. Gerber L, Otgonsuren M, Mishra A, et al. Non-alcoholic fatty liver disease (NAFLD) is associated with low level of physical activity: a population-based study. Alimentary of Pharmacology and Therapeutics. 2012;36(8):772-81.

30. Sato N. Central role of mitochondria in metabolic regulation of liver pathophysiology. Journal of Gasteroenterology and Hepatology. 2007;22(s1):S1-6.

31. Hu FB. Sedentary lifestyle and risk of obesity and type 2 diabetes. Lipids. 2003:38(2):103-8.

32. Hu FB, Li TY, Colditz GA, Willett WC, Manson JE. Television watching and other sedentary behaviors in relation to risk of obesity and type 2 diabetes mellitus in women. JAMA. 2003;289(14):1785-91.

33. Dunstan DW, Thorp AA, Healy GN. Prolonged sitting: is it a distinct coronary heart disease risk factor? Curr Opin Cardiol. 2011;26(5):412-9.

34. Zelber-Sagi S, Ratziu V, Oren R. Nutrition and physical activity in NAFLD: an overview of the epidemiological evidence. World J Gastroenterol. 2011; 17(29):3377.
35. St George A, Bauman A, Johnston A, Farrell G, Chey T, George J. Independent effects of physical activity in patients with nonalcoholic fatty liver disease. Hepatology (Baltimore Md). 2009;50(1):68-76.

36. Sreenivasa Baba C, Alexander G, Kalyani B, et al. Effect of exercise and dietary modification on serum aminotransferase levels in patients with nonalcoholic steatohepatitis. Journal of Gasteroenterology and Hepatology. 2006;21(1 Pt 1):191-8.

37. Angulo P. Obesity and nonalcoholic fatty liver disease. Nutr Rev. 2007;65: S57-63.

38. Angulo P. NAFLD, obesity, and bariatric surgery. Gastroenterology. 2006; 130(6):1848-52.

39. Boule NG, Haddad E, Kenny GP, Wells GA, Sigal RJ. Effects of exercise on glycemic control and body mass in type 2 diabetes mellitus: a meta-analysis of controlled clinical trials. JAMA. 2001;286(10):1218-27.

40. Goodyear $\amalg$, Kahn BB. Exercise, glucose transport, and insulin sensitivity. Annu Rev Med. 1998;49:235-61.

41. Hannukainen JC, Nuutila P, Borra R, et al. Increased physical activity decreases hepatic free fatty acid uptake: a study in human monozygotic twins. J Physiol. 2007:578(Pt 1):347-58.

\section{Publisher's Note}

Springer Nature remains neutral with regard to jurisdictional claims in published maps and institutional affiliations.
Ready to submit your research? Choose BMC and benefit from:

- fast, convenient online submission

- thorough peer review by experienced researchers in your field

- rapid publication on acceptance

- support for research data, including large and complex data types

- gold Open Access which fosters wider collaboration and increased citations

- maximum visibility for your research: over $100 \mathrm{M}$ website views per year

At BMC, research is always in progress.

Learn more biomedcentral.com/submissions 